\title{
Mitral stenosis obscuring the diagnosis of plexogenic pulmonary arteriopathy and familial pulmonary hypertension
}

David Langleben, Esther Lamoureux, Francois Marcotte, Robert Schlesinger,
Leonidas Dragatakis, Marie Josee Crowe, Yves Langlois, Francois Lemire, Michel White

\begin{abstract}
A patient who died after surgery for critical mitral stenosis was found to have underlying unrecognised plexogenic pulmonary arteriopathy and familial pulmonary hypertension. The importance of recognising familial pulmonary hypertension is discussed, together with the contribution of genetic and other risk factors to plexogenic pulmonary arteriopathy.
\end{abstract}

(Thorax 2000;55:247-248)

Keywords: plexogenic pulmonary arteriopathy; mitral stenosis; familial pulmonary hypertension; primary pulmonary hypertension

Plexogenic pulmonary arteriopathy with the formation of plexiform lesions is common in primary pulmonary hypertension and secondary pulmonary hypertension resulting from left-to-right intracardiac shunts, HIV disease, and anorexigen use. ${ }^{1-4}$ Mitral stenosis is a classic cause of postcapillary pulmonary hypertension. ${ }^{5}$ The increased pulmonary arterial pressure may be passive in response to increased left atrial pressure. ${ }^{6}$ However, in many patients excessive medial thickening and intimal fibrosis develop, resulting in higher pulmonary arterial pressures. ${ }^{2} 7$ Plexiform lesions are not usually found with mitral stenosis. $^{2}$ We describe a case of coexisting mitral stenosis and plexogenic pulmonary arteriopathy and provide an explanation for this unusual coincidence.

\section{Case report}

The patient was a 50 year old non-smoking woman who had suffered for 1.5 years from progressive dyspnoea, with no history of phlebitis, anorexigen intake, or autoimmune disease. There was no cyanosis or clubbing and her chest was clear. Her jugular venous pressure was $11 \mathrm{~cm} \mathrm{H}_{2} \mathrm{O}$ without peripheral oedema. Her $\mathrm{P}_{2}$ was loud but there were no gallops, murmurs, or opening snaps.

Haematological and biochemical parameters were within the normal range. An electrocardiogram showed right heart strain and a chest radiograph showed cardiomegaly, clear lung fields, prominent pulmonary arteries, and a small left pleural effusion. Echocardiography revealed thickened rheumatic mitral leaflets with severe mitral stenosis (mitral valve area $0.9 \mathrm{~cm}^{2}$ ), enlarged right sided chambers with moderate tricuspid regurgitation, paradoxical septal mo- tion, a mildly enlarged left atrium, a small left ventricle, and no intracardiac shunting.

Cardiac catheterisation indicated that the coronary arteries were normal. Her pulmonary artery pressure (Ppa) was 98/45 (mean 65) $\mathrm{mm} \mathrm{Hg}$, mean wedge pressure was $16 \mathrm{~mm} \mathrm{Hg}$, and left ventricular end diastolic pressure was $8 \mathrm{~mm} \mathrm{Hg}$. The mean diastolic mitral valve gradient determined by planimetry was $7.7 \mathrm{~mm} \mathrm{Hg}$ with a cardiac output of $2.15 \mathrm{l} / \mathrm{min}$ resulting in a calculated mitral valve area of $0.76 \mathrm{~cm}^{2}$.

At surgery her mitral valve was found to be severely stenosed and was replaced with a prosthetic valve. Despite intra-aortic balloon support to both ventricles and intravenous prostacyclin and milrinone, her pulmonary arterial pressures were persistently increased, she was unable to maintain an adequate cardiac output, and died.

Necroscopic examination showed no evidence of organised clot in the proximal pulmonary arteries. There was enlargement of the right sided cardiac chambers and left atrium without septal defects. The mitral valve was severely thickened with chordal fusion, consistent with past rheumatic disease. Microscopic examination of numerous lung sections revealed severe arterial medial thickening and intimal fibrosis. However, numerous classic plexiform lesions were also observed (fig 1).

The patient's only child had a heart murmur in infancy. Cardiac catheterisation at two years and nine months showed pulmonary hypertension (Ppa 40/16 mm Hg, mean wedge pressure $6 \mathrm{~mm} \mathrm{Hg}$ ) with mild hypertrophic obstruction of the mid right ventricle and no evidence of intracardiac shunting. The clinicians at that time felt that this was an "unusual clinical and haemodynamic situation" because of the unexplained pulmonary hypertension. At the age of 10 the hypertrophic myocardial muscle was resected and a small $(3 \mathrm{~mm})$ ventricular septal defect was closed with a single stitch. The Ppa preoperatively was $70 / 40 \mathrm{~mm} \mathrm{Hg}$. Five years later a repeat cardiac catheterisation showed a right ventricular systolic pressure of $60 \mathrm{~mm} \mathrm{Hg}$. The pulmonary artery could not be entered due to basilic vein spasm. She was lost to follow up until the age of 19 when she presented with severe pulmonary hypertension (Ppa 120/70 mm Hg) unresponsive to vasodilators. Her clinical state worsened rapidly and she died while awaiting transplantation. Necroscopic examination was not performed. 

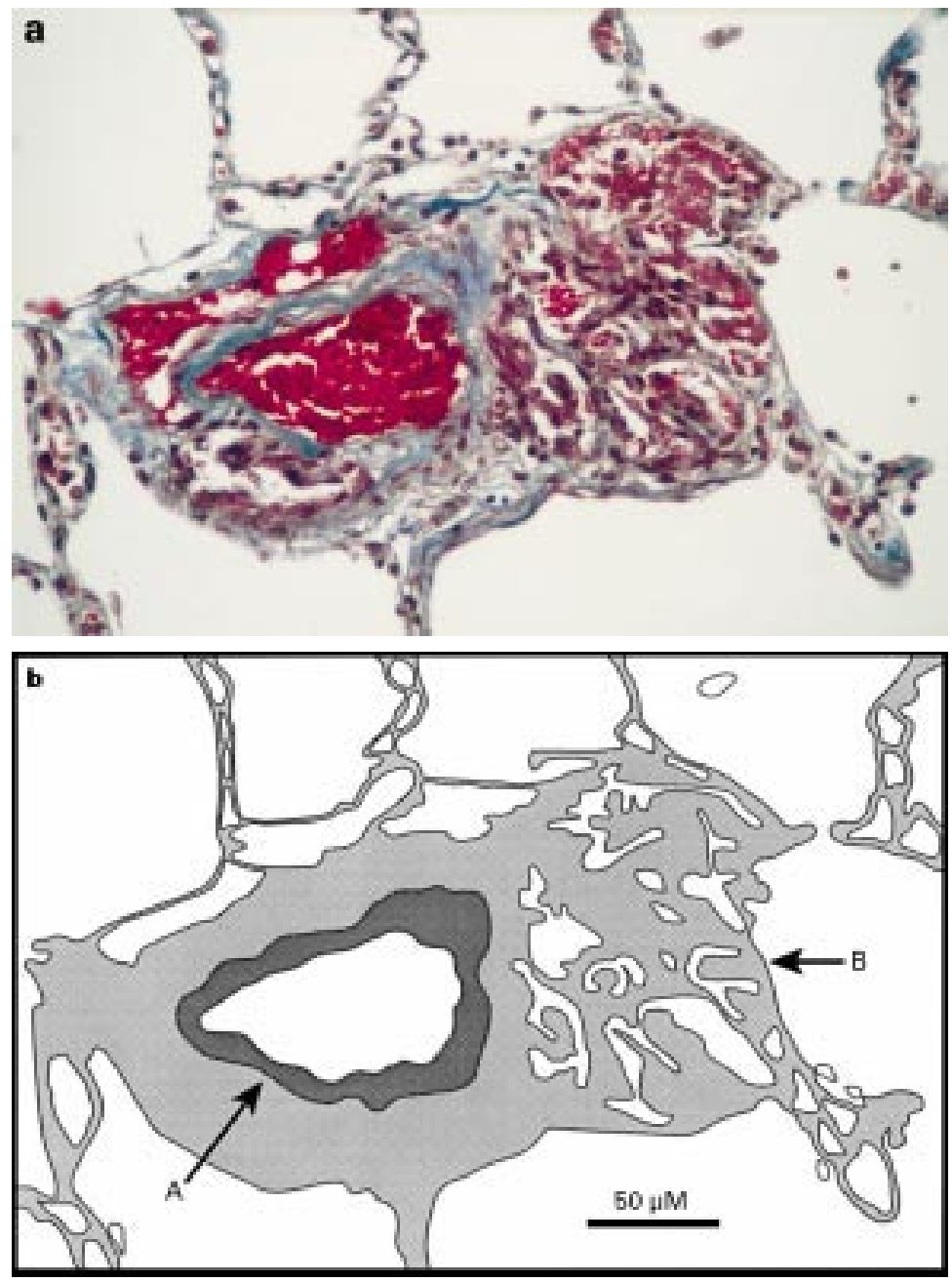

Figure 1 (a) Photomicrograph and (b) drawing showing a mature plexiform lesion (B) adjacent to a small pulmonary artery $(A)$. Multiple vascular channels are seen with intervening thin fibrous septae. Their lumina contain erythrocytes and fibrinous material (majority of grey areas in b). Trichrome stain, original magnification $\times 250$.

\section{Discussion}

Pulmonary hypertension is frequently seen with mitral stenosis and it usually improves rapidly after mitral valve replacement or valvuloplasty. ${ }^{5}$ The failure of the patient's pulmonary hypertension to diminish postoperatively or with vasodilators was unexpected and fatal. It is unlikely that mitral stenosis was the cause of her advanced plexogenic pulmonary arteriopathy since plexiform lesions have never been described in the hundreds of reported cases of mitral stenosis and pulmonary hypertension, ${ }^{27}$ even in the presence of severe pulmonary hypertension..$^{9-13}$

It is more likely that she had a latent genetic predisposition to develop plexogenic arteriopathy or primary pulmonary hypertension, which either occurred independently of, or was accelerated by, the mitral stenosis. Variable susceptibility to development of plexogenic pulmonary arteriopathy may be genetic. In familial primary pulmonary hypertension successive generations may manifest the disease at earlier ages due to genetic anticipation, ${ }^{14}$ and a genetic locus on chromosome 2 has recently been described. ${ }^{15}{ }^{16}$ Similarly, secondary pulmonary hypertension and plexogenic pulmonary arteriopathy from HIV infection or anorexigen intake develops in only a few patients, which suggests variable susceptibility in the face of a provoking factor. ${ }^{34}$ In support of a familial predisposition to unexplained pulmonary hypertension, the patient's daughter developed precocious primary pulmonary hypertension. Her haemodynamically insignificant ventricular septal defect, undetectable by oximetry at the age of two years and nine months, should not itself have induced her pulmonary vasculopathy without an underlying genetic predisposition. Moreover, the progression in the daughter's pulmonary hypertension several years after closure of the ventricular septal defect also suggests an underlying predisposition.

Reports such as this one illustrate the importance of careful analysis of atypical cases of pulmonary hypertension, ${ }^{17}$ particularly when patient management has been difficult, in order to identify plexogenic pulmonary arteriopathy (or primary pulmonary hypertension) obscured by or masquerading as other disorders. An understanding of the genetics of plexogenic pulmonary arteriopathy will further help in its diagnosis and treatment. ${ }^{14}$

Funding: Dr Langleben is a Chercheur-Boursier Clinicien (Research Scholar) of the Fonds de la Recherche en Sante du Quebec.

This work was supported in part by the Bank of Montreal Center for the study of heart disease in women.

1 Hatano S, Strasser T. Primary pulmonary hypertension. Report of a WHO meeting. Geneva: World Health Organization, 1975: 7-45.

2 Harris P, Heath D. The human pulmonary circulation. Its form and function in health and disease. 3rd ed. Edinburgh: Churchill Livingstone, 1986: 247-61, 298-302, 340.

3 Brenot F, Herve P, Petitprez P, et al. Primary pulmonary hypertension and fenfluramine use. Br Heart $\mathcal{F}$ 1993;70: 537-41

4 Speich R, Jenni R, Opravil M, et al. Primary pulmonary hypertension in HIV infection. Chest 1991;100:1268-71.

5 Braunwald E, Braunwald NS, Ross Jr J, et al. Effects of mitral valve replacement on the pulmonary vascular dynamics of patients with pulmonary hypertension. $N$ Engl f Med 1965;273:509-14.

6 Braunwald E, Moscovitz HL, Amram SS, et al. The hemodynamics of the heart as studied by simultaneous left atrial, left ventricular, and aortic pressures; particular reference to mitral stenosis. Circulation 1955;12:69-81.

7 Tandon HD, Kasturi J. Pulmonary vascular changes associated with isolated mitral stenosis in India. Br Heart f 1975; 37:26-36.

8 Dalen JE, Matloff JM, Evans GL, et al. Early reduction of pulmonary vascular resistance after mitral-valve replacement. N Engl 7 Med 1967;277:387-94.

9 Hutchins GM, Ostrow PT. The pathogenesis of the two forms of hypertensive pulmonary vascular disease. $\mathrm{Am}$ Heart f 1976;92:797-803.

10 Wagenvoort CA, Wagenvoort N. Smooth muscle content of pulmonary arterial media in pulmonary venous hypertension compared with other forms of pulmonary hypertension. Chest 1982;81:581-5.

11 Heath D, Edwards JE. Histologic changes in the lung in diseases associated with pulmonary venous hypertension. $B r \mathcal{F}$ Dis Chest 1959;53:8-18.

12 Ramirez A, Grimes ET, Abelmann WH. Regression of pulmonary vascular changes following mitral valvuloplasty. Am f Med 1968;45:975-82.

13 Kay JM, Edwards FR. Ultrastructure of the alveolarcapillary wall in mitral stenosis. F Pathol 1973;111:239-45.

14 Langleben D. Familial primary pulmonary hypertension. Chest 1994;105:13-16S.

15 Nichols WC, Koller DL, Slovis B, et al. Localization of the gene for familial primary pulmonary hypertension to chrogene for familial primary pulmonary hypertension
mosome 2q31-32. Nature Genet 1997;15:277-80.

16 Morse JH, Jones AC, Barst RJ, et al. Mapping of familial primary pulmonary hypertension locus (PPH1) to chromosome 2q31-32. Circulation 1997;95:2603-6.

17 Mendelsohn ME, Cole P, St John Sutton M. Double mitral valve orifice and primary pulmonary hypertension. Int $\mathcal{F}$ Cardiol 1989;22:261-4. 